\title{
Biological and synthetic mesh use in breast reconstructive surgery: a literature review
}

\author{
Hugh Logan Ellis ${ }^{1 *}$, Oluwatosin Asaolu², Vivien Nebo ${ }^{2}$ and Abdul Kasem
}

\begin{abstract}
Mesh use in surgical breast reconstruction is becoming increasingly common; however, there is still no consensus on whether synthetic matrices or biological matrices produce the best outcomes. This review analyses these outcomes, namely the differences in aesthetic outcomes, cost, and the rates of the most commonly reported complications.

The results indicate that breast reconstruction with a synthetic matrix produces comparable aesthetic outcomes to a biological matrix, with lower costs and complication rates. The individual results for complication rates show that biological matrixes are associated with lower infection rates and slightly lower capsular contracture, but higher haematoma rates, and slightly higher rates of skin necrosis and explantation-although many had post-op radiotherapy. The majority of the studies evaluated used biological matrices, and there are no randomised controlled trials directly comparing the two types of meshes; definite conclusions cannot be drawn from the available evidence. The authors suggest that a randomised controlled trial comparing these outcomes in synthetic and biological matrix use is needed.
\end{abstract}

Keywords: Breast reconstruction, Synthetic, Biological, Matrix, Mesh, Aesthetic outcomes, Cost, Complications

\section{Background}

In England, around $40 \%$ of breast cancer patients opt for mastectomy as their primary therapeutic management [1]. Of the 18,000 mastectomies performed in England and Wales [2], $21 \%$ undergo immediate reconstruction [1].

Surgical breast reconstruction (BR) post-mastectomy was first performed in 1895 by Vincent Czerny using a "fist-sized lipoma from the patient's flank" [3]. Since then, various improvements have been made to $B R$, including the introduction of immediate-as opposed to delayed-reconstruction, which has shown significantly improved aesthetic outcomes [4], psychological health, and increased quality of life [5]. Numerous surgical techniques have been developed, including the use of autologous tissue flaps, most commonly from the abdomen and the back or silicone implants with or without prior insertion of a tissue expander (TE) [6]. As with any surgical procedure, there are complications. These will be discussed in some depth in this review.

More recently, biological and synthetic matrices have emerged as a useful adjunct to BR.

\footnotetext{
* Correspondence: hughloganellis@cantab.net

'Medway Maritime Hospital, Gillingham, Kent, UK

Full list of author information is available at the end of the article
}

A biological mesh-also referred to as an acellular dermal matrix (ADM) - is a scaffold of dermis produced from cadaveric human (Alloderm ${ }^{\circ}$, Allomax ${ }^{\circ}$, FlexHD ${ }^{\circ}$, DermaCell $\left.{ }^{\circ}\right)$, porcine (Strattice ${ }^{\circ}$, Permacol $\left.^{\mathrm{m}}{ }^{\mathrm{N}}\right)$, bovine $\left(\right.$ SurgiMend $\left.{ }^{\circ}\right)$, or bovine pericardium $\left(\right.$ Veritas $\left.^{\circ}\right)$ tissue that is stripped of its antigenic cells through specialised processing [7]. The biological scaffold allows rapid host revascularisation and cell repopulation arguably facilitating a good surgical outcome.

Most studies have reviewed biological matrices in implant-based reconstruction, acting as an extension of the pectoralis major muscle $[8,9]$. By attaching to the inferior-lateral pole of the muscle, the mesh expands the space available for the insertion of an implant, filling the void left between the muscle and fascia, thereby creating a natural inframammory fold (see Fig. 1) [10]. This technique provides additional cover and support inferiorly, enabling faster tissue expansion, larger implant volumes, and improvement of lower pole projection [11].

Despite the advantages of ADMs, they do not come without complication. These include infection, cellulitis, seroma, haematoma, skin flap necrosis, wound dehiscence, capsular contracture, implant extrusion/exposure, and explantation/implant loss [12]. In addition, studies

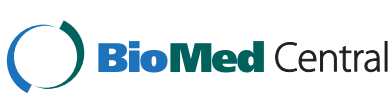

(C) 2016 Logan Ellis et al. Open Access This article is distributed under the terms of the Creative Commons Attribution 4.0 International License (http://creativecommons.org/licenses/by/4.0/), which permits unrestricted use, distribution, and reproduction in any medium, provided you give appropriate credit to the original author(s) and the source, provide a link to the Creative Commons license, and indicate if changes were made. The Creative Commons Public Domain Dedication waiver (http://creativecommons.org/publicdomain/zero/1.0/) applies to the data made available in this article, unless otherwise stated. 


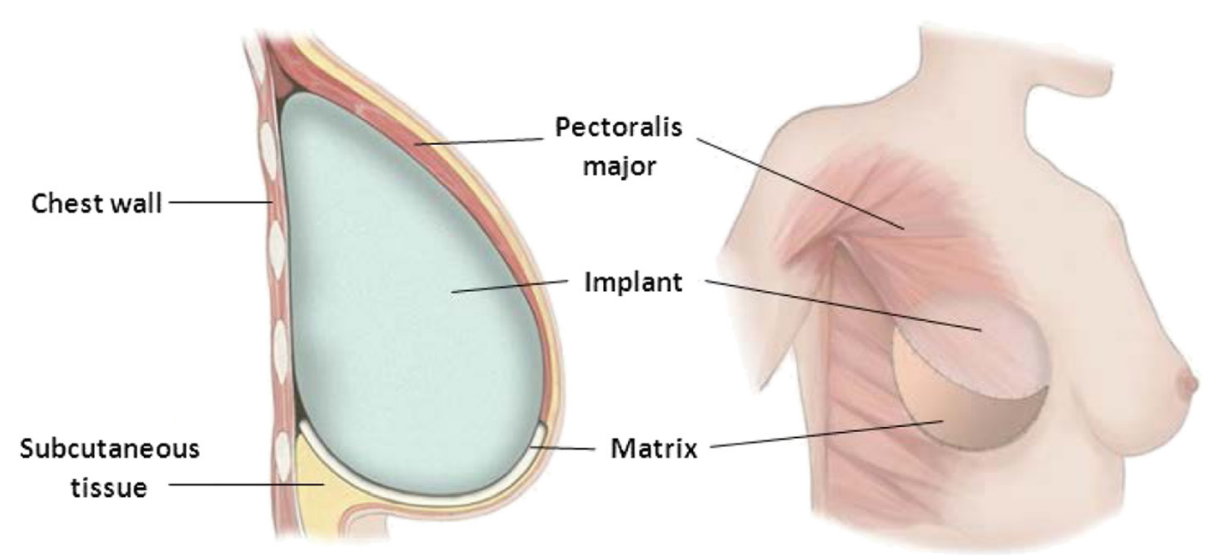

Fig. 1 Placement of biological matrix. Adapted image showing the placement of the matrix (biological or synthetic) between the inferior pole and the aponeurosis of the pectoralis major muscle. The matrix is supporting the lower pole of the breast, while expanding the implant pocket, providing increased coverage of the implant [97]

have shown adverse effects associated with radiotherapy, as well as high cost $[8,9]$ when ADMs are used.

Recent studies are now investigating the use of lowcost synthetic matrices in BR as an alternative to ADMs [10]. Synthetic matrices are made from plastic-like material: absorbable (Vicryl), long-term absorbable (TIGR ${ }^{\circ}$ ), or non-absorbable (titanium-coated polypropylene mesh $\left(\right.$ TiLOOP $\left.^{\oplus}\right)$ ). Although these synthetic meshes play a similar role to ADMs in BR, it remains unclear whether the complication rates between synthetic and biological matrices differ, as currently, there are no studies comparing them.

This literature review will compare synthetic and biological meshes use in BR, comparing differences in aesthetic outcomes, cost, and the most commonly reported complications.

\section{Method}

A literature search was conducted with the view of identifying articles relevant to a retrospective review of biological and synthetic matrices used in BR postmastectomy. PubMed was used as a search engine. The terms entered were the following: "breast reconstruction AND mesh," "breast reconstruction AND acellular dermal matrix," "breast reconstruction AND Strattice," "breast reconstruction AND synthetic mesh," "breast reconstruction AND Vicryl," "breast reconstruction AND TIGR," and "breast reconstruction AND TiLOOP." The results from this search were limited to articles published between January 2004 and March 2014, giving 519 results.

These articles were then screened for eligibility according to the inclusion and exclusion criteria. Studies involving BR post-mastectomy (whether immediate or delayed) that used a mesh for the reconstruction were included. In addition, some in vitro and in vivo articles, as well as those providing histological analysis, were included.
Papers were excluded if their focus was the use of mesh on the following areas: abdominal reinforcement post-BR, chest wall reconstruction, and the revision of primary and secondary deformities.

The study method, number of subjects, type of mastectomy (skin-sparing, nipple-sparing, total, modified radical, radical, or extended radical), type of mesh (biological or synthetic), type of reconstruction (immediate or delayed), surgical technique (direct-to-implant/single-stage or TEbased/two-stage), and the results including any complications were all recorded.

A full table of all the literature evaluated in this review can be found as Additional file 1 .

\section{Results}

Each study was evaluated for specific outcomes, namely aesthetic outcomes, cost, complication rates and effects of radiotherapy.

\section{Aesthetic outcomes}

The literature shows positive aesthetic outcomes associated with the use of ADMs in surgical BR [11, 13-19]. Specifically, Vardanian et al. [13] reported higher overall aesthetic outcomes when an ADM was placed, compared to no matrix, with statistically reduced bottoming-out $(p=0.002)$, rippling $(p=0.011)$, and mechanical shift $(p=0.011)$ [13]. A retrospective review by Gamboa-Bobadilla et al. [14] reported good and excellent aesthetic outcomes in $91 \%$ of subjects just 14 months after an implant-based BR with ADM. In line with this, Spear et al. [15] reported aesthetic outcomes comparable to non-surgery controls after undergoing expander-based BR. While Forsberg et al. [11] found statistically significant improvements in natural contour, symmetry of shape and size, position on chest wall, and overall aesthetic outcomes, when ADM was used in expander-based BR compared to without. 
Similar aesthetic results have been reported with the use of synthetic matrices. A study by Kim and Cho [20] evaluating the use of the absorbable Vicryl mesh in implantbased BR described excellent/good cosmetic outcome in $91 \%$ of patients. While a retrospective review by Rietjens et al. [21] reported an average symmetry of 7.56, a patient satisfaction of 7.75, and a surgeon cosmetic evaluation of 7.60 (all rated out of 10), 28 months after expanderbased BR using a non-absorbable mesh (Mersilene).

\section{Cost}

The high cost of matrices is one factor that continues to be a deterrent to their use in BR [22]. A single sheet can range anywhere between \$1825 [9] and \$4856 [8], depending on its size and thickness, although increasing competition between types of ADM has helped reduced this [22]. An advantage of ADM use is direct-to-implant BR. This technique does not require tissue expansion before implant insertion, prevents the donor site morbidity and lengthy recovery time associated with autologous flap reconstruction, and reduces operating time substantially, compared with autologous flap and expander-based BR [23]. Johnson et al. [23] showed that the placement of a unilateral implant with Strattice mesh produced a total cost of $£ 3685$ for the surgery per patient, which was significantly lower than unilateral TE (£4985) and latissimus dorsi flap (£6321) implant-based BR surgery. These numbers indicate that despite the extra cost of an ADM, it may reduce the overall cost of surgery.

Newer studies have begun to consider the use of synthetic matrices as a low-cost alternative to ADMs in BR. A recent retrospective review conducted by Tessler et al. [10] revealed direct material cost savings of $\$ 172,112$ over a 10-month period with the use of synthetic mesh (Vircyl) in implant-based BR, when compared directly to ADM expenses at the authors' institution.

\section{Complication rates}

Mesh use in BR is associated with many complications [24-29]. Of these, infection, seroma, haematoma, capsular contracture, skin flap necrosis, and explantation or implant loss were the most commonly reported.

It has been shown several times that ADM use is associated with an increased risk of complications in BR surgery and more recent studies have analysed the complication rate when synthetic meshes are used $[10,20,21,24-26,30,31]$. However, there are currently no articles in the literature directly comparing the complication rates between these two types of mesh.

Patient characteristics have been associated with increased complication rates in $\mathrm{BR}$ in general, with or without mesh use [32-34]. These include age ( $>65$ years), large breasts (>600 g), obesity (body mass index >30), smoking, diabetes, hypertension, and long drain removal time. Although it is important to consider these factors, it is clear that these occur regardless of whether or not a mesh is used. Appropriate patient selection and individualisation of reconstructive options are needed to account for any co-morbidities and risk factors that may be present among patients.

\section{Infection}

Infection is one of the most common complications seen in both biological and synthetic mesh use, which often leads to tissue necrosis, and may result in explantation, revision, or even complete loss of implant $[10,24,35,36]$. Dieterich et al. [24] have conducted the largest study $(n=$ 207, 231 cases) using a synthetic mesh (TiLOOP ${ }^{\circ}$ ) in implant-based BR to date, producing an overall infection rate of $6.1 \%$, of which only $1.7 \%$ needed revision. Other studies of synthetic mesh use in BR have revealed lower rates of infection (1.3-4.7\%) [10, 20, 21, 26, 31], and two papers reported no cases of infection at all $[25,31]$.

A large retrospective review by Ibrahim et al. [37] of 19,100 subjects undergoing implant-based BR showed a lower infection rate of $3.3 \%$ in subjects where ADMs were used $(n=3301)$. A meta-analysis by Kim et al. [38] of 19 papers $(n=2037)$ comparing the submuscular TE technique with human ADM BR showed an infection rate of $5.3 \%$ with ADM use. This was reported as a relative risk of 2.47 (95\% confidence interval (CI), 1.71-3.57), when compared to the submuscular group. The remaining studies analysed reported a rate ranging between 0.2 and $35.8 \%$ [11, 13, 23, 27, 39-59], with four studies reporting no complications of infection [16, 60-62]-although this could be attributed to the relatively low subject numbers.

An explanation for these findings is offered by a highthroughput assay comparing synthetic (Prolene and Vicryl) and biological (AlloDerm and FlexHD) matrices as substrates for bacterial adhesion, which concluded that Staphylococcus aureus adhered more readily to ADMs than synthetic matrices [63]. In addition, post-operative antibiotic prophylaxis following mesh BR, as trialled by Avashia et al. [64], has shown some promise in reducing infection rates from 31.6 to $11.1 \%(p=0.004)$ in participants who underwent implant-based reconstruction using ADM.

\section{Seroma and haematoma}

Seroma and haematoma are commonly occurring complications associated with surgical BR and can both lead to an increased risk of infection and tissue necrosis, particularly when large enough to require drain insertion [28] which carries the risk of TE or implant puncture.

Seroma is an especially detrimental problem in TEbased BR, where its development between the pectoralis major muscle/mesh layer and the breast tissue envelope (see Fig. 2) may result in a poor aesthetic outcome upon exchange to implant [28]. 


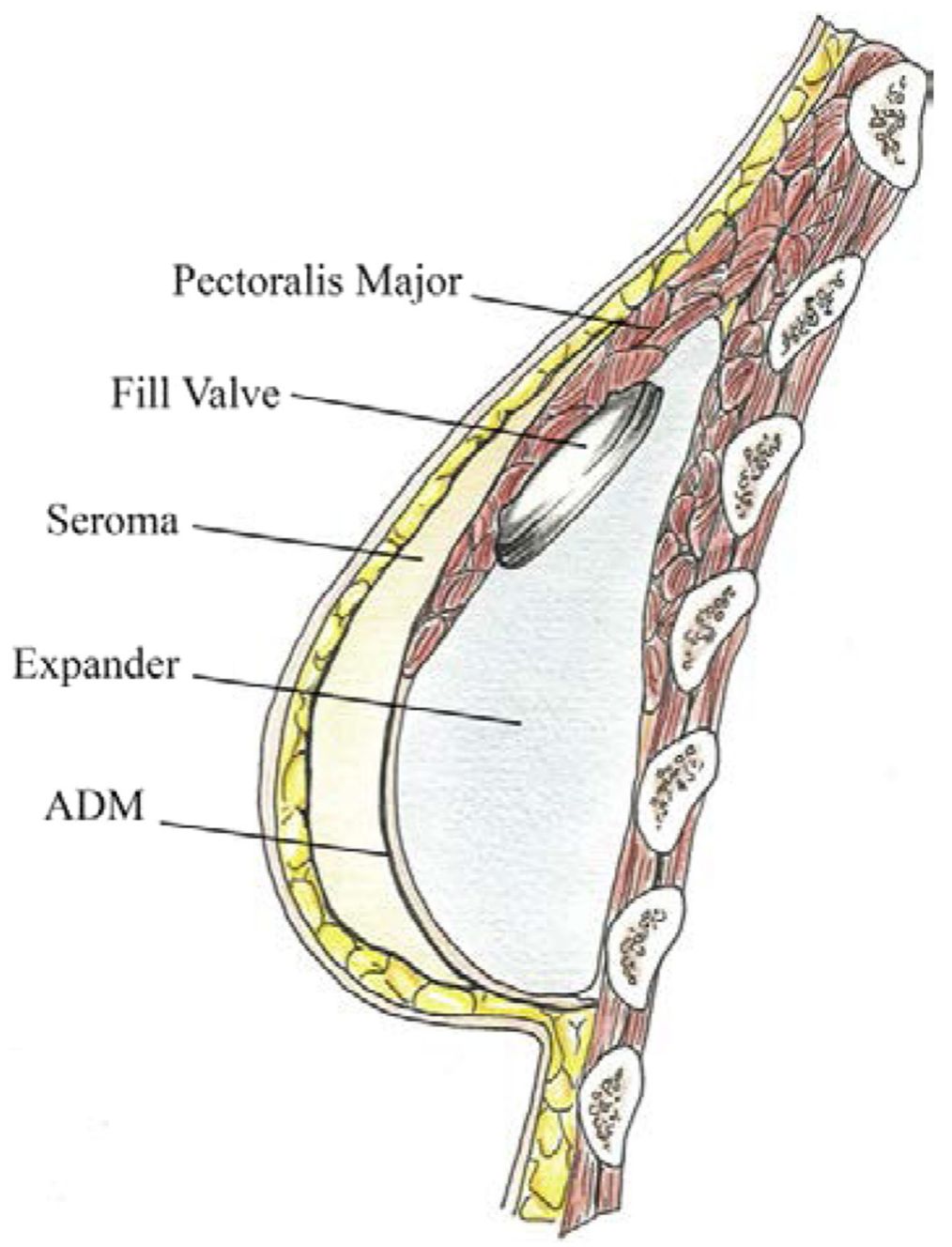

Fig. 2 Seroma formation. Animated image of seroma development between breast tissue envelope and pectoralis major/mesh (ADM) layer [28]

Haematoma formation is thought to occur in the immediate post-operative period as a result of trauma during surgery-although the use of electrocautery has significantly reduced this [65] — or as a late complication due to small tears in the capsule formed around the TE/implant, often after physical trauma [66-68].

Seroma formation in association with synthetic mesh use in surgical BR has been evaluated in six different studies $[10,20,24-26,30]$ and ranges from no seroma development [10] to $5.7 \%$ [20]. Dieterich et al. [24], the largest ( $n=207,231$ cases) and therefore perhaps the most reliable study of synthetic mesh (TiLOOP) use to date, revealed an overall seroma rate of $4.8 \%$, although only $1.4 \%$ required revision. Dietrich et al. also found the highest rate of haematoma, at $9.5 \%$, treated with either puncture or compression. Other studies looking at the use of synthetic mesh in BR showed haematoma rates of $0-4.7 \%[10,25,26]$.
The presence of seroma as a complication of ADM use in BR was found to range widely between $1.5 \%$ [54] and $24.3 \%$ [23], in the studies that evaluated it as a complication. The meta-analysis by Kim et al. [38] was the largest $(n=2037)$ study to report the rates of seromas in BR with ADM. Their results showed a seroma rate of $4.8 \%$ with a relative risk of 2.73 (95\% CI, 1.67-4.46). Haematoma formation after BR with ADM produced a smaller range of $0-11.1 \%[17,27,29,69,70]$, the highest of which was reported by Moyer et al. [27], where all participants received radiotherapy.

\section{Capsular contracture}

Capsular contracture is described as the formation of a fibrous capsule around the implant, which may contract, compressing the implant as it thickens progressively, resulting in a hard breast with deformed contouring of the surrounding skin [71]. This may result in severe pain, 
due to nerve entrapment, or muscle mobility interference. Although the aetiology is unclear, some believe that it is initiated by blood products like haematomas [72], while others consider infection and chronic inflammation to be most likely cause [73] - either by bacteria colonisation from within the ductal breast tissue or the skin.

The Baker classification system is used to assess the severity of capsular contracture in a clinical setting, with classes ranging from I to IV [74]. A clinically significant outcome is usually only associated with a Baker class of III (moderate firmness) or IV (symptomatic with severe firmness), although most studies note all levels of contracture. Before the introduction of ADM use, high rates of capsule contracture were frequently reported [72]. With the advent of ADM, studies have reported significantly lower rates of capsular contracture $[13,15,18,19$, $32,39,49,51,69,75]$, although no studies have directly compared the incidence of capsular contracture between synthetic and biological matrices.

Of the five studies that evaluated the rate of capsular contracture in cases of BR with synthetic mesh, Tessler et al. [10] reported the lowest rate of contracture needing revision, at $1.3 \%$, while the highest rate of severe contracture leading to pain was $8.6 \%$-seen by Kim and Cho [20]. Rietjens et al. [21] reported the highest overall rate of capsule contracture at $68.4 \%$; however, only $13.7 \%$ of these were graded as Baker class III or IV. It should also be noted that a non-absorbable mesh (Mersilene) was used-a type of synthetic mesh that has been reported to produce rigidity [30]. Loustau et al. [25] were the only authors to report no capsular contracture.

In keeping with the literature described above, the majority of the studies reported little or no capsular contracture (six studies), ranging between 0.4 and $8.1 \%$ [11, 39] when ADM was used. Moyer et al. [27] studied the effect of radiation on ADM and capsule formation, revealing a very high rate of Baker class III/IV capsular contracture of $33.3 \%(n=27)$.

Studies of the histological changes ADM use [76-79] support the hypothesis that ADMs-due to their lack of antigenic epitopes-provide a barrier to the host immune response against a foreign body (the expander/implant) and reduce capsular formation and contracture risk [76]. Komorowska-Timek et al. [79] studied the effect of an ADM on capsule formation with and without radiation and concluded that ADM reduces radiation-related inflammation and pseudoepithelium formation, resulting in slower progression of capsular formation and contraction. The incidence of capsular contracture in human subjects where ADM has been used also shows significantly reduced contracture problems, histologically [77] and clinically [78].

Few studies have evaluated the histological outcomes upon use of synthetic matrices in surgical BR. Dieterich et al. [80] produced a case report and histological analysis on the use of TiLOOP ${ }^{\circ}$ in BR, showing mild inflammation, indicating a low risk of capsular contracture.

\section{Skin necrosis}

Skin necrosis and breakdown in the context of BR is multifactorial; patient co-morbidities, thin mastectomy skin flaps, or overexpansion may contribute [12]. When overexpansion occurs, there is a risk of loss of vascular supply to the overlying mastectomy skin flap, resulting in ischaemic changes [81].

Three studies have reported the occurrence of skin necrosis in BR with synthetic mesh. Becker and Lind [30] conducted a retrospective review using the TIGR matrix in $\mathrm{BR}$, revision, and cosmetic surgery, finding skin flap necrosis in $1.8 \%$ of participants $(n=62,112$ reconstructions). Two separate studies conducted by Dieterich et al. [26] and [24] showed skin necrosis of 2.4 and $4.3 \%$ (0.4\% of which was native to the mastectomy flap), respectively.

Clemens and Kronowitz [41] showed higher rates of skin necrosis in BR with ADM (34.2\%). However, of the remaining studies collected evaluating this complication with ADM use, only five other studies produced rates in this vicinity $(23.7-28.3 \%)[18,29,36,45,82]$. All other studies found skin necrosis rates below $12.5 \%$ $[19,42,44,75,83]$, with Strattice showing skin necrosis rates of only $1.4-2.9 \%[44,84]$.

\section{Explantation and implant loss}

All of the above complications, if severe enough, may lead to TE or implant explantation, often resulting in complete implant loss. Dieterich et al. [24] revealed the highest $(8.7 \%)$ rate of implant loss of the four studies evaluating this in BR when synthetic mesh was used [10, 21, 24, 26], while Tessler et al. [10] reported the lowest implant loss rate of $1.3 \%$, when using the Vicryl mesh.

Thirty-nine studies evaluated explantation and implant loss in BR with ADM, ranging from 0 to $33.3 \%$ $[18,27,29,85]$. Despite this high value, majority of the studies within this range showed comparable rates of implantation loss to those with synthetic mesh use $[42,44,76,86]$.

\section{Effect of radiotherapy}

Radiotherapy has a significantly detrimental effect on most BR outcomes, whether given pre- or post-reconstruction $[15,20,30,49,58,82]$ and diminishes neovascularisation and mesh incorporation into the host [87].

In regard to aesthetic outcome post-radiotherapy, Kim and Cho [20] reported a significant reduction in excellent/good aesthetic outcomes from 91 to $60 \%$, when the Vicryl mesh was used in implant-based reconstruction. 
Similarly, Hanna et al. [49] reported reduced patient satisfaction after their expander-based reconstruction with ADM.

In addition, increased rates of complications in participants who received radiotherapy before and after surgery have been reported in several studies [15, 24, 30, 82]. Becker and Lind [31] showed that $44 \%$ of irradiated subjects that received radiotherapy developed postreconstruction complications when TIGR was used. Dieterich et al. [24] reported that the TiLOOP mesh was more palpable in irradiated patients but barely palpable in non-irradiated patients who had very thin mastectomy flaps.

Spear et al. [15], Brooke et al. [58], and Pestana et al. [82] all showed a significant increase in overall complication rates when ADMs were used. Spears et al. found a difference in complications of $42.1 \%(p=0.002)$ between irradiated and non-irradiated patients. Other studies showed specific increases in infection [88] and implant loss $[53,89,90]$ when radiation was given to subjects who had BR with an ADM [88, 89]. This correlates with results again by Spear et al. [59], showing higher rates of contracture and increased rates of implant loss upon expander exchange, in patients to whom radiotherapy was given.

Studies in animals [79] and human subjects [27, 40, 57] have reported a protective effect against radiotherapy associated with ADM in comparison to without mesh. Moyer et al. [27] showed a reduced elastosis and chronic inflammation of the breast capsules of six patients, when compared to non-irradiated controls. Similarly, Seth et al. [57] found that ADM BR was associated with lower risk of all complications due to radiation, when compared to non-ADM BR.

\section{Discussion}

The major limitation of this review is that no studies known to the authors have directly compared the use of synthetic and biological matrices in BR. It is therefore very difficult to make any concrete comparisons between the two types of mesh. However, some conclusions have been drawn relating to the outcomes evaluated in the results, using the limited data available.

Aesthetic outcome is a commonly reported endpoint in BR and influences patient satisfaction post-BR significantly [21]. The results above showed high rates of positive aesthetic outcomes in both biological and synthetic matrices.

Although synthetic matrices are being evaluated as cheaper alternatives to biological matrices, the benefits of using ADMs in BR may outweigh the high costs discussed in the results [22]. One positive feature that distinguishes ADMs from synthetic matrices is the ability to incorporate into the host tissue [91]. This incorporation has been shown to parallel normal wound healing [92], allowing for tissue remodelling and regeneration [93].

The results comparing complication rates between meshes must be discussed separately. It appears that the use of synthetic matrices in BR is associated with a lower rate of infection compared to ADM use. However, no statistical methods have been used to take into account any outliers that may have increased the wide range of infection rate when using biological mesh. In addition, it appears that not all ADMs are equal; long-term sterility could be one of the reasons for the wide range of infection rates seen, with studies showing reduced infection rates when comparing sterile to non-sterile ADMs used in BR [61], even when aseptic techniques are strictly adhered to [36]. Notably, the number of studies found evaluating the rate of infection when using ADM is eightfold more than those reporting infection as a complication of BR with synthetic mesh. Therefore, while synthetic matrices in BR seem to have a lower associated infection rate, more studies evaluating this are needed to make a definite conclusion.

This leads to the second major limitation-the paucity of studies reporting the outcomes associated with the use of synthetic mesh in BR. Although various studies have evaluated the use of synthetic mesh in abdominal hernia repair [94-96], more research is needed into breast reconstructive surgery. It is likely that this not only affected the evaluation of infection rates but also influenced all of the outcomes to an extent-particularly capsular contracture, skin necrosis, and explantation/implant loss.

Two studies evaluating capsular contracture produced significantly outliers; the synthetic mesh evaluated by Rietjens et al. [21] may have caused bias in the clinical evaluation of capsular contracture due to its rigidity, leading to the high contracture rates reported above. The second outlier was reported by Moyer et al. [27], with a capsular contracture rate fourfold higher than the other 17 studies with ADM, which was attributed to a small sample size $(n=27)$. Upon exclusion of these outliers, a slightly higher range of capsular contracture was reported with synthetic mesh, suggesting that the biological matrix may give a small advantage against capsular contracture. However, many more studies have been published analysing the association between BR with ADM than with synthetic mesh.

Similarly, many more studies have evaluated skin necrosis and explantation/implant loss in association with biological than synthetic matrices. This must be taken in account when looking at the results of these two complications and may indicate that the use of synthetic mesh in BR produces lower rates of skin necrosis and explantation. It is again unlikely that a true representation of the rates of explantation/implant loss with ADM has 
been obtained, as the higher end of the range (0-33.3 \%) was due to nine patients in Moyer et al. [27], all of whom were exposed to radiotherapy, which as discussed has detrimental effects on the results. It is hoped that as the evidence of the use of synthetic mesh increases, a more accurate picture of the actual rates of skin necrosis, explantation/implant loss, and capsular contracture will be possible.

Although the ranges produced from the data evaluating seroma formation significantly differ, the two largest studies evaluating this complication when using synthetic and biological matrices in BR obtained the exact same rate of this complication [24, 38]. This suggests that there may be little difference between the rates of seroma occurrence when comparing the two types of mesh. On the other hand, the rates of haematoma formation were greater in $\mathrm{BR}$ with $\mathrm{ADM}$ compared to synthetic matrices. However, it is unclear how much influence the effects of radiotherapy may have had on this complication, particularly as many studies did not clearly state which incidences of haematoma were associated with the administration of radiotherapy, the effects of which have been discussed above.

Both types of mesh showed similar rates of increased complications in BR when radiotherapy was administered; however, ADMs may be more beneficial in this case, due to the apparent protective effect that has been discussed above. It could be argued that irradiation is an independent risk factor for complications in BR; outcomes in the literature investigating $\mathrm{ADM}$ use in the setting of radiation therapy are mixed.

Further limitations include variations between surgical techniques at both different sites and between different surgeons, which likely added noise to the data. In addition, the mastectomy type, type of mesh, type of reconstruction, and surgical technique were noticeably different between the studies. The lengths of follow-up period also varied considerably. Lastly, majority of the studies included were retrospective observational studies; therefore, it is unlikely that all the patient characteristics would have been adequately matched to rule out this bias.

\section{Conclusions}

The overall consensus from the data presented shows that BR with synthetic matrices produces comparable aesthetic outcomes to ADMs, with lower costs and complication rates. However, in the absence of RCTs evaluating these outcomes, it is difficult to make any definite conclusions, particularly as the vast majority of published data on this topic looked at ADM use in BR. Further studies-particularly comparing the two types of mesh-are indicated, and a randomised controlled trial between synthetic and biological matrices is recommended by the authors. It could be argued that biological meshes are still leading the field at this point in time: their ability to incorporate into the host tissue, the small advantage they pose against capsular contracture, and their arguments for a protective effect against irradiation. In light of this, some might reason that these positives outweigh the negatives, and biological meshes could be considered over synthetic matrices in BR surgery.

\section{Additional file}

Additional file 1: A complete table of all the studies compared. (DOCX $96 \mathrm{~kb})$

\section{Abbreviations}

ADM: acellular dermal matrix; BR: breast reconstruction; Cl: confidence interval; TE: tissue expander.

\section{Competing interests}

A. Kasem is a consultant general surgeon, who specialises in breast reconstruction.

\section{Authors' contributions}

VN and OA carried out the literature search and drafted the manuscript. HLE participated in the design and co-ordination and helped to draft the manuscript. AK conceived the study and offered guidance to the other authors. All authors read and approved the final manuscript.

\section{Author details}

${ }^{1}$ Medway Maritime Hospital, Gillingham, Kent, UK. ${ }^{2}$ King's College London University, London, UK.

Received: 29 October 2015 Accepted: 13 April 2016

Published online: 21 April 2016

References

1. National Mastectomy and Breast Reconstruction Audit. A national audit of provision and outcomes of mastectomy and breast reconstruction surgery for women in England. Report no. Fourth Annual Report. Leeds: Health and Social Care Information Centre. 2011.

2. NHS choices. Mastectomy, http://www.nhs.uk/conditions/mastectomy/ pages/introduction.aspx (2012, Accessed 16 Mar 2014).

3. Uroskie TW, Colen LB. History of breast reconstruction. Semin Plast Surg. 2004;18:65-9.

4. McCarthy CM, Pusic AL, Disa JJ, et al. Unilateral postoperative chest wall radiotherapy in bilateral tissue expander/implant reconstruction patients: a prospective outcomes analysis. Plast Reconstr Surg. 2005;116:1642-7.

5. Drucker-Zertuche M, Robles-Vidal C. A 7 year experience with immediate breast reconstruction after skin sparing mastectomy for cancer. Eur J Surg Oncol. 2007;33:140-6.

6. Ahmed S, Snelling A, Bains M, et al. Breast reconstruction. BMJ. 2005;330:943-8.

7. LifeCell. AlloDerm ${ }^{\circledast}$ Regenerative Tissue Matrix, http://www.lifecell.com/healthcare-professionals/lifecell-products/allodermr-regenerative-tissue-matrix/ (2014, Accessed 16 Mar 2014)

8. Hartzell TL, Taghinia AH, Chang J, et al. The use of human acellular dermal matrix for the correction of secondary deformities after breast augmentation: results and costs. Plast Reconstr Surg. 2010;126:1711-20.

9. Becker S, Saint-Cyr M, Wong C, et al. AlloDerm versus DermaMatrix in immediate expander-based breast reconstruction: a preliminary comparison of complication profiles and material compliance. Plast Reconstr Surg. 2009; 123:1-6. discussion 107-8.

10. Tessler O, Reish RG, Maman DY, et al. Beyond biologics: absorbable mesh as a low-cost, low-complication sling for implant-based breast reconstruction. Plast Reconstr Surg. 2014;133:90e-9.

11. Forsberg CG, Kelly DA, Wood BC, et al. Aesthetic outcomes of acellular dermal matrix in tissue expander/implant-based breast reconstruction. Ann Plast Surg. 2014;72(6):S116-20. 
12. Israeli R. Complications of acellular dermal matrices in breast surgery. Plast Reconstr Surg. 2012;130:159S-72.

13. Vardanian AJ, Clayton JL, Roostaeian J, et al. Comparison of implant-based immediate breast reconstruction with and without acellular dermal matrix. Plast Reconstr Surg. 2011;128:403e-10.

14. Gamboa-Bobadilla GM. Implant breast reconstruction using acellular dermal matrix. Ann Plast Surg. 2006;56:22-5.

15. Spear SL, Parikh PM, Reisin E, et al. Acellular dermis-assisted breast reconstruction. Aesthetic Plast Surg. 2008;32:418-25.

16. Breuing $\mathrm{KH}$, Warren SM. Immediate bilateral breast reconstruction with implants and inferolateral AlloDerm slings. Ann Plast Surg. 2005; 55:232-9.

17. Salzberg CA. Nonexpansive immediate breast reconstruction using human acellular tissue matrix graft (AlloDerm). Ann Plast Surg. 2006;57:1-5.

18. Zienowicz RJ, Karacaoglu E. Implant-based breast reconstruction with allograft. Plast Reconstr Surg. 2007;120:373-81.

19. Bindingnavele V, Gaon M, Ota KS, et al. Use of acellular cadaveric dermis and tissue expansion in postmastectomy breast reconstruction. J Plast Reconstr Aesthet Surg. 2007;60:1214-8.

20. Kim T, Cho H. The suitability of absorbable mesh insertion for oncoplastic breast surgery in patients with breast cancer scheduled to be irradiated. J Breast Cancer. 2013;16:84-9.

21. Rietjens $M$, De Lorenzi $F$, Venturino $M$, et al. The suspension technique to avoid the use of tissue expanders in breast reconstruction. Ann Plast Surg. 2005;54:467-70.

22. Sbitany $\mathrm{H}$, Langstein $\mathrm{HN}$. Acellular dermal matrix in primary breast reconstruction. Aesthet Surg J. 2011;31:30S-7.

23. Johnson RK, Wright CK, Gandhi A, et al. Cost minimisation analysis of using acellular dermal matrix (Strattice) for breast reconstruction compared with standard techniques. Eur J Surg Oncol. 2013;39:242-7.

24. Dieterich M, Paepke S, Zwiefel K, et al. Implant-based breast reconstruction using a titanium-coated polypropylene mesh (TiLOOP Bra): a multicenter study of 231 cases. Plast Reconstr Surg. 2013;132:8e-19.

25. Loustau HD, Mayer HF, Sarrabayrouse M. Immediate prosthetic breast reconstruction: the ensured subpectoral pocket (ESP). J Plast Reconstr Aesthet Surg. 2007;60:1233-8

26. Dieterich $M$, Reimer $T$, Dieterich $H$, et al. A short-term follow-up of implant based breast reconstruction using a titanium-coated polypropylene mesh (TiLoop((R)) Bra). Eur J Surg Oncol. 2012;38:1225-30.

27. Moyer HR, Pinell-White $X$, Losken $A$. The effect of radiation on acellular dermal matrix and capsule formation in breast reconstruction: clinical outcomes and histologic analysis. Plast Reconstr Surg. 2014;133:214-21.

28. Moyer KE, Potochny JD. Technique for seroma drainage in implant-based breast reconstruction. J Plast Reconstr Aesthet Surg. 2012;65:1614-7.

29. Jansen LA, Macadam SA. The use of AlloDerm in postmastectomy alloplastic breast reconstruction: part I. A systematic review. Plast Reconstr Surg. 2011;127:2232-44.

30. Becker $\mathrm{H}$, Lind 2nd JG. The use of synthetic mesh in reconstructive, revision, and cosmetic breast surgery. Aesthetic Plast Surg. 2013;37:914-21.

31. Rulli A, Caracappa D, Castellani E, et al. Optimizing therapeutic timing in patients undergoing mastectomy through use of the Tiloop(R) synthetic mesh: single-step surgery. In Vivo. 2013;27:383-6.

32. Lanier ST, Wang ED, Chen JJ, et al. The effect of acellular dermal matrix use on complication rates in tissue expander/implant breast reconstruction. Ann Plast Surg. 2010;64:674-8.

33. McCarthy CM, Mehrara BJ, Riedel E, et al. Predicting complications following expander/implant breast reconstruction: an outcomes analysis based on preoperative clinical risk. Plast Reconstr Surg. 2008;121:1886-92.

34. Endress R, Choi MS, Lee GK. Use of fetal bovine acellular dermal xenograft with tissue expansion for staged breast reconstruction. Ann Plast Surg. 2012;68:338-41.

35. Topol BM, Dalton EF, Ponn T, et al. Immediate single-stage breast reconstruction using implants and human acellular dermal tissue matrix with adjustment of the lower pole of the breast to reduce unwanted lift. Ann Plast Surg. 2008;61:494-9.

36. Weichman KE, Wilson SC, Saadeh PB, et al. Sterile "ready-to-use" AlloDerm decreases postoperative infectious complications in patients undergoing immediate implant-based breast reconstruction with acellular dermal matrix. Plast Reconstr Surg. 2013;132:725-36.

37. Ibrahim AM, Shuster M, Koolen PG, et al. Analysis of the National Surgical Quality Improvement Program database in 19,100 patients undergoing implant-based breast reconstruction: complication rates with acellular dermal matrix. Plast Reconstr Surg. 2013;132:1057-66.
38. Kim JY, Davila AA, Persing S, et al. A meta-analysis of human acellular dermis and submuscular tissue expander breast reconstruction. Plast Reconstr Surg. 2012;129:28-41.

39. Salzberg CA, Ashikari AY, Koch RM, et al. An 8-year experience of directto-implant immediate breast reconstruction using human acellular dermal matrix (AlloDerm). Plast Reconstr Surg. 2011;127:514-24.

40. Peled AW, Foster RD, Garwood ER, et al. The effects of acellular dermal matrix in expander-implant breast reconstruction after total skin-sparing mastectomy: results of a prospective practice improvement study. Plast Reconstr Surg. 2012;129:901e-8.

41. Clemens MW, Kronowitz SJ. Acellular dermal matrix in irradiated tissue expander/implant-based breast reconstruction: evidence-based review. Plast Reconstr Surg. 2012:130:27S-34.

42. Adetayo OA, Salcedo SE, Bahjri K, et al. A meta-analysis of outcomes using acellular dermal matrix in breast and abdominal wall reconstructions: event rates and risk factors predictive of complications. Ann Plast Surg. 2011 Dec 9. [Epub ahead of print]

43. Spear SL, Sinkin JC, Al-Attar A. Porcine acellular dermal matrix (strattice) in primary and revision cosmetic breast surgery. Plast Reconstr Surg. 2013;131:1140-8.

44. Salzberg CA, Dunavant C, Nocera N. Immediate breast reconstruction using porcine acellular dermal matrix (Strattice): long-term outcomes and complications. J Plast Reconstr Aesthet Surg. 2013;66:323-8.

45. Ganske I, Verma K, Rosen $\mathrm{H}$, et al. Minimizing complications with the use of acellular dermal matrix for immediate implant-based breast reconstruction. Ann Plast Surg. 2013;71:464-70.

46. Sbitany H, Sandeen SN, Amalfi AN, et al. Acellular dermis-assisted prosthetic breast reconstruction versus complete submuscular coverage: a head-to-head comparison of outcomes. Plast Reconstr Surg. 2009;124:1735-40.

47. Antony AK, McCarthy CM, Cordeiro PG, et al. Acellular human dermis implantation in 153 immediate two-stage tissue expander breast reconstructions: determining the incidence and significant predictors of complications. Plast Reconstr Surg. 2010;125:1606-14.

48. Newman MI, Swartz KA, Samson MC, et al. The true incidence of near-term postoperative complications in prosthetic breast reconstruction utilizing human acellular dermal matrices: a meta-analysis. Aesthetic Plast Surg. 2011;35:100-6.

49. Hanna KR, DeGeorge Jr BR, Mericli AF, et al. Comparison study of two types of expander-based breast reconstruction: acellular dermal matrix-assisted versus total submuscular placement. Ann Plast Surg. 2013;70:10-5.

50. Collis GN, TerKonda SP, Waldorf JC, et al. Acellular dermal matrix slings in tissue expander breast reconstruction: are there substantial benefits? Ann Plast Surg. 2012;68:425-8.

51. Cassileth L, Kohanzadeh S, Amersi F. One-stage immediate breast reconstruction with implants: a new option for immediate reconstruction. Ann Plast Surg. 2012; 69:134-8.

52. Ho G, Nguyen TJ, Shahabi A, et al. A systematic review and meta-analysis of complications associated with acellular dermal matrix-assisted breast reconstruction. Ann Plast Surg. 2012:68:346-56.

53. Kobraei EM, Nimtz J, Wong L, et al. Risk factors for adverse outcome following skin-sparing mastectomy and immediate prosthetic reconstruction. Plast Reconstr Surg. 2012;129:234e-41.

54. Colwell AS, Damjanovic B, Zahedi B, et al. Retrospective review of 331 consecutive immediate single-stage implant reconstructions with acellular dermal matrix: indications, complications, trends, and costs. Plast Reconstr Surg. 2011;128:1170-8

55. Sbitany H, Serletti JM. Acellular dermis-assisted prosthetic breast reconstruction: a systematic and critical review of efficacy and associated morbidity. Plast Reconstr Surg. 2011;128:1162-9.

56. Hoppe IC, Yueh JH, Wei CH, et al. Complications following expander/implant breast reconstruction utilizing acellular dermal matrix: a systematic review and meta-analysis. Eplasty. 2011;11:e40

57. Seth AK, Hirsch EM, Fine NA, et al. Utility of acellular dermis-assisted breast reconstruction in the setting of radiation: a comparative analysis. Plast Reconstr Surg. 2012;130:750-8

58. Brooke $\mathrm{S}$, Mesa J, Uluer $\mathrm{M}$, et al. Complications in tissue expander breast reconstruction: a comparison of AlloDerm, DermaMatrix, and FlexHD acellular inferior pole dermal slings. Ann Plast Surg. 2012;69:347-9.

59. Spear SL, Seruya M, Rao SS, et al. Two-stage prosthetic breast reconstruction using AlloDerm including outcomes of different timings of radiotherapy. Plast Reconstr Surg. 2012;130:1-9.

60. Selber JC, Clemens MW Oates $S$, et al. Autoderm: an alternative bioprosthetic for breast reconstruction. Plast Reconstr Surg. 2013;131:985-7. 
61. Losken A. Early results using sterilized acellular human dermis (neoform) in postmastectomy tissue expander breast reconstruction. Plast Reconstr Surg. 2009 Mar 23. [Epub ahead of print].

62. Breuing $\mathrm{KH}$, Colwell AS. Immediate breast tissue expander-implant reconstruction with inferolateral AlloDerm hammock and postoperative radiation: a preliminary report. Eplasty. 2009;9:e16.

63. Nyame $\mathrm{T}$, Lemon KP, Kolter R, et al. High-throughput assay for bacterial adhesion on acellular dermal matrices and synthetic surgical materials. Plast Reconstr Surg. 2011;128:1061-8.

64. Avashia YJ, Mohan R, Berhane C, et al. Postoperative antibiotic prophylaxis for implant-based breast reconstruction with acellular dermal matrix. Plast Reconstr Surg. 2013;131:453-61.

65. Vitug AF, Newman LA. Complications in breast surgery. Surg Clin North Am 2007:87:431-51. X.

66. Gorgu M, Aslan G, Tuncel A, et al. Late and long-standing capsular hematoma after aesthetic breast augmentation with a saline-filled silicone prosthesis: a case report. Aesthetic Plast Surg. 1999:23:443-4.

67. Hsiao HT, Tung KY, Lin CS. Late hematoma after aesthetic breast augmentation with saline-filled, textured silicone prosthesis. Aesthetic Plast Surg. 2002;26:368-71.

68. Veiga DF, Filho JV, Schnaider CS, et al. Late hematoma after aesthetic breast augmentation with textured silicone prosthesis: a case report. Aesthetic Plast Surg. 2005:29:431-3. discussion 434.

69. Breuing $\mathrm{KH}$, Colwell AS. Inferolateral AlloDerm hammock for implant coverage in breast reconstruction. Ann Plast Surg. 2007:59:250-5.

70. Spear SL, Seruya M, Clemens MW, et al. Acellular dermal matrix for the treatment and prevention of implant-associated breast deformities. Plast Reconstr Surg. 2011;127:1047-58.

71. Araco A, Caruso R, Araco F, et al. Capsular contractures: a systematic review. Plast Reconstr Surg. 2009;124:1808-19.

72. Bengtson B. Discussion: use of dermal matrix to prevent capsular contracture in aesthetic breast surgery. Plast Reconstr Surg. 2012;130:1375-41.

73. Schreml S, Heine N, Eisenmann-Klein M, et al. Bacterial colonization is of major relevance for high-grade capsular contracture after augmentation mammaplasty. Ann Plast Surg. 2007:59:126-30.

74. Spear SL, Baker Jr JL. Classification of capsular contracture after prosthetic breast reconstruction. Plast Reconstr Surg. 1995;96:1119-23. discussion 1124.

75. Namnoum JD. Expander/implant reconstruction with AlloDerm: recent experience. Plast Reconstr Surg. 2009;124:387-94

76. Hester Jr TR, Ghazi BH, Moyer HR, et al. Use of dermal matrix to prevent capsular contracture in aesthetic breast surgery. Plast Reconstr Surg. 2012; 130:126S-36.

77. Basu CB, Leong M, Hicks MJ. Acellular cadaveric dermis decreases the inflammatory response in capsule formation in reconstructive breast surgery. Plast Reconstr Surg. 2010;126:1842-7.

78. Koltz PF, Frey JD, Langstein HN. The use of human acellular dermal matrix in the first stage of implant-based breast reconstruction simplifies the exchange procedure. Plast Reconstr Surg. 2013;132:691e-2.

79. Komorowska-Timek E, Oberg KC, Timek TA, et al. The effect of AlloDerm envelopes on periprosthetic capsule formation with and without radiation. Plast Reconstr Surg. 2009;123:807-16

80. Dieterich $\mathrm{M}$, Dieterich $\mathrm{H}$, Timme S, et al. Using a titanium-coated polypropylene mesh (TiLOOP((R)) Bra) for implant-based breast reconstruction: case report and histological analysis. Arch Gynecol Obstet. 2012;286:273-6.

81. Crosby $M A$, Dong $W$, Feng $L$, et al. Effect of intraoperative saline fill volume on perioperative outcomes in tissue expander breast reconstruction. Plast Reconstr Surg. 2011;127:1065-72.

82. Pestana IA, Campbell DC, Bharti G, et al. Factors affecting complications in radiated breast reconstruction. Ann Plast Surg. 2013;70:542-5.

83. Seth AK, Persing S, Connor CM, et al. A comparative analysis of cryopreserved versus prehydrated human acellular dermal matrices in tissue expander breast reconstruction. Ann Plast Surg. 2013;70:632-5.

84. Glasberg SB, Light D. AlloDerm and Strattice in breast reconstruction: a comparison and techniques for optimizing outcomes. Plast Reconstr Surg 2012;129:1223-33.

85. Venturi ML, Mesbahi AN, Boehmler 4th $\mathrm{JH}$, et al. Evaluating sterile human acellular dermal matrix in immediate expander-based breast reconstruction: a multicenter, prospective, cohort study. Plast Reconstr Surg. 2013;131:9e-18.

86. Johnson JK, Haider F, Ellis K, et al. The prevalence of domestic violence in pregnant women. BJOG. 2003;110:272-5.
87. Kasem A, Choy C, Mokbel K. Skin-sparing mastectomy and breast reconstruction: an update for clinical practice. J Cancer Ther. 2014;5:264-80.

88. Reish RG, Damjanovic B, Austen Jr WG, et al. Infection following implant-based reconstruction in 1952 consecutive breast reconstructions: salvage rates and predictors of success. Plast Reconstr Surg. 2013;131:1223-30.

89. Potter S, Chambers A, Govindajulu S, et al. Early complications and implant loss in implant-based breast reconstruction with and without acellular dermal matrix (Protexa(R)): a comparative study. Eur J Surg Oncol. 2015; 41(1):113-9.

90. Parks JW, Hammond SE, Walsh WA, et al. Human acellular dermis versus no acellular dermis in tissue expansion breast reconstruction. Plast Reconstr Surg. 2012;130:739-46.

91. Ibrahim AM, Ayeni OA, Hughes KB, et al. Acellular dermal matrices in breast surgery: a comprehensive review. Ann Plast Surg. 2013;70:732-8.

92. Wong AK, Schonmeyr B, Singh $\mathrm{P}$, et al. Histologic analysis of angiogenesis and lymphangiogenesis in acellular human dermis. Plast Reconstr Surg. 2008;121:1144-52

93. LifeCell. Tissue regeneration, http://www.lifecell.com/health-care-professionals/ lifecell-products/allodermr-regenerative-tissue-matrix/allodermr-tissue-matrixdefined/tissue-regeneration/ (2003, Accessed 9 Apr 2014).

94. Lallement M, Missana MC, Bourgeon Y, et al. Closure of the abdominal wall after removal of a mucocutaneous flap from the transverse rectus abdominis for breast reconstruction. Apropos of 48 cases. Review of the literature. Ann Chir Plast Esthet. 1994;39:733-41.

95. Pinell-White XA, Kapadia SM, Losken A. The management of abdominal contour defects following TRAM flap breast reconstruction. Aesthet Surg J. 2014:34:264-71.

96. Svaerdborg M, Damsgaard TE. Donor-site morbidity after pedicled TRAM breast reconstruction: a comparison of two different types of mesh. Ann Plast Surg. 2013;71:476-80.

97. Centre for Breast Cancer Surgery. Breast implant with tissue matrix, http:/www. pyramide.ch/en/Zentrum-fur-Brustkrebschirurgie/Behandlungsangebot/ Brustrekonstruktionstechniken/Brustimplantat-mit-Gewebematrix (2014, Accessed 17 Apr 2014).

\section{Submit your next manuscript to BioMed Central and we will help you at every step:}

- We accept pre-submission inquiries

- Our selector tool helps you to find the most relevant journal

- We provide round the clock customer support

- Convenient online submission

- Thorough peer review

- Inclusion in PubMed and all major indexing services

- Maximum visibility for your research

Submit your manuscript at www.biomedcentral.com/submit 